NBER WORKING PAPER SERIES

\title{
FISCAL INCREASING RETURNS, HYSTERESIS, REAL WAGES \\ AND UNEMPLOYMENT
}

Olivier J. Blanchard

Lawrence $H$. Summers

Working Paper No. 2034

NATIONAL BUREAU OF ECONOMIC RESEARCH

1050 Massachusetts Avenue

Cambridge, MA 02138

October 1986

We are grateful to Michael Emerson for useful discussions and to Lousie Sheiner for research assistance. The research reported here is part of the NBER's research program in Economic Fluctuations. Any opinions expressed are those of the authors and not those of the National Bureau of Economic Research. 
NBER Working Paper \#2034

October 1986

Fiscal Increasing Returns, Hysteresis, Real Wages and Unemployment

\section{ABSTRACT}

European unemployment is widely regarded as a problem of excessive real wages. This view as it is usually expressed carries the disturbing implication that there is a sharp conflict between the interests of those currently employed and the unemployed because it suggests that increases in employment will require reductions in the real wages of those currently employed. The first part of this paper shows that increases in employment in Europe are likely to be associated with rising real take-home pay for workers because of fiscal increasing returns. Increases in employment and output will make possible reductions in taxes sufficiently large to offset any effects of diminishing returns to labor.

The second part of the paper considers alternative explanations for the failure of nominal wages to adjust so as to restore full employment and their implications for the efficacy of fiscal policies. It concludes that under a variety of plausible conditions tax cuts would succeed in stimulating employment.

Olivier J. Blanchard Department of Economics MIT

Cambridge, MA 02139
Lawrence $H$. Summers Department of Economics Harvard University Cambridge, MA 02138 
European unemployment is widely regarded as a problem of excessive real wages. The conventional wisdom is that at current real wages with the current capital stock, the labor force cannot all be employed profitably. This conclusion is often illustrated by the calculation of wage gaps, estimates of the amount by which real wages would have to fall for full employment in Europe to be restored, given the levels of the capital stock and technology. The efficacy of expansionary aggregate demand policy is a subject of controversy, with those who see it as useful often acknowledging that it can only succeed by reducing real wages. Skeptics suggest that real wages are sufficiently rigid that demand polices will not succeed in reducing real wages appreciably and will therefore increase prices but not employment.

The real wage view of the unemployment problem as it is usually stated carries the disquieting implication that there is a sharp conflict between the interests of those currently employed and those currently unemployed. It implies that a return to full employment in Europe will require sacrifices on the part of workers who are currently employed. Many policy discussions focus on methods of getting currently employed workers to accept reductions in their standard of living so that more people can be employed. It is hardly surprising that labor organizations, which represent primarily those with jobs, do not enthusiastically join these discussions. Thus, for half a decade now policymakers have tried to bring about real wage reductions through the use of contractionary demand policies. The results have not been encouraging. Unemployment has doubled in the EEC from its already high 1980 level.

In the first part of this paper we question the validity of the view that a return to full employment requires sacrifices on the part of currently 
employed workers. We note that it depends critically on the assumption of diminishing returns in the production of output for private consumption. As long as there are diminishing returns, durable increases in the level of employment necessarily imply reductions in the amount of output available per worker at least as long as profits do not decline. With increasing returns however, increases in employment will lead to more than proportionate increases in output--making possible increases in the consumption of employed workers. Increasing returns may arise through a number of channels. While discussions of increasing returns usually focus on the form of the production function, we focus on fiscal increasing returns arising from the presence of a large public sector. This may well be, for macroeconomics, the most important type of increasing returns.

If, as unemployment decreases, government spending does not increase in proportion with economic activity, an assumption which is particularly likely to hold in Europe at the present time, government spending is just like a public fixed cost. An increase in output allows for a decrease in tax rates, and an increase in after-tax wages given pre-tax wages. We show the effect to be quantitatively substantial. Indeed, we think it very likely that in the major European countries an increase in employment would be associated with increases in after tax real wages. Conversely, if after tax real wages are fixed, tax cuts might well prove so expansionary as to be self financing. If an increase in employment is consistent with an increase in real wages and can make both the currently unemployed and the currently employed workers better off, why doesn't it take place? We take this question up in the second 
part of the paper. Ultimately, the answer must be found in the failure of nominal wages to decline sufficiently in the face of unemployment. A decline in nominal wages and prices would eventually lead to an increase in aggregate demand and an increase in output and employment, together with higher real take-home wages. But this has not happened; indeed, one of the major developments over the last five years in Europe has been the increase in the level of unemployment consistent with no pressure on wages, the increase in the "NAIRU". The problem of explaining why universally beneficial increases in employment do not take place becomes that of explaining the high current level of the NAIRU.

A popular explanation for the high level of the NAIRU has been the rigidity of real wages at excessively high levels. We consider the implications of this view for tax policy, but ultimately conclude that it does not provide a fully satisfactory explanation for the persistence of high unemployment. Relying on our earlier work (Blanchard and Summers 1986) we therefore consider theories of macroeconomic hysteresis. The essential element of these theories is the assumption that wages are mostly set in the interests of currently employed insiders, not of unemployed outsides. We have shown in our previous work how these theories can easily explain the increase in the NAIRU in line with the increase in actual unemployment. More importantly here, when this assumption is coupled with the assumption of decentralized wage bargaining, it generates exactly the type of nominal wage rigidity that needs to be explained. While a general decrease in nominal wages would be beneficial to all, insiders and outsiders alike, no individual group of insiders has an 
incentive to decrease its nominal wage, given the nominal wages bargained by the other group; it would only lead to the hiring of some outsiders, an outcome that is not beneficial to the insiders.

We conclude by considering the implications of our analysis for economic policy. In the absence of strong policy measures, European unemployment is likely to remain high for the foreseeable future. If however, by demand expansion or social contracts, policy can increase employment, a return to steady full employment is possible without asking concessions from the currently employed. We argue that whatever explanation is provided for the current high level of unemployment, substantial tax cuts are likely to have a significant positive impact on employment and need not be associated with more than a temporary increase in budget deficits.

\section{Section I. Fiscal increasing returns}

In this section we examine fiscal increasing returns--the increasing returns arising from the fixed nature of the government's claim on the economy's output. In order to focus on the effects of fiscal increasing returns, we assume perfect competition in the goods market, constant returns to scale in capital and labor, and that the capital stock is fixed over the horizon being analyzed. These are not our preferred assumptions but are familiar and so permit us to isolate the implications of fiscal increasing returns. Relaxing them by allowing for increasing returns in the production function and imperfect competition in product markets, or for the accumulation 
of capital, would strengthen the conclusions reached here.

We assume that the government acts so as to maintain the level of the budget deficit constant as unemployment is reduced. On the spending side, we allow for the fact that employment expansion reduces spending on unemployment insurance and welfare, but neglect the possibility that increased revenues from economic expansion would be used to create new government programs. This latter assumption seems appropriate at this stage, given the political climate in Europe. Our assumption that increases in output would not lead to changes in budget deficits seems fairly realistic for the medium term analysis contemplated here. Recent decreases in output have actually been associated with declines in budget deficits. Budget deficits, adjusted for inflation, have slowly gone down, from -2.98 of GDP for the EC average in 1982 to a forecast -1.78 for 1986. Such levels are well below levels which would require urgent further adjustment.

The relationships between real wages, employment and taxes are then given by the simple system:

$$
\begin{aligned}
& Y=F(L) ; F^{\prime}>0, F^{\prime \prime} \leq 0 \\
& G-b w_{0}\left(1-t_{0}\right)\left(L-L_{0}\right)=t Y \\
& F^{\prime}(L)=w
\end{aligned}
$$

Equation ( 1 ) is a production function, giving output as a function of employment with a given capital stock. Equation (2) gives the government budget constraint, with spending on the left, and revenues on the right. Spending is a 
decreasing function of the level of employment, as unemployment insurance decreases with the level of employment. The parameter $b$ represents the replacement rate provided by unemployment insurance expressed as a fraction of after tax wages. ${ }^{1}$ Taxes are assumed to be levied on output, or equivalently on both wage and profit income. The tax rate $t$ is therefore endogenously determined by the need to finance government spending, which itself declines with employment. Equation (3) gives the relation between employment and wages which follows from profit maximization under perfect competition.

\section{Employment and after tax real wages}

One cannot, in the absence of a labor supply or wage setting equation, determine from (1) to (3) both the wage and the level of employment. But one can derive the relation between the two. Using (1) to (3), the relation between employment and the take home pay of workers, $w_{h}$, is given by :

$$
w_{h}=(1-t) w-\left[\left(F(L)-G+b w_{0}\left(1-t_{0}\right)\left(L-L_{0}\right)\right]\left(F^{\prime}(L) / F(L)\right)\right.
$$

Under strictly decreasing returns, $w_{h}$ is first an increasing and then a decreasing function of $\mathrm{L}$. When employment is low, the decrease in taxes which follows from a larger tax base dominates the effect of decreasing returns in production. When employment is high, the effect of decreasing returns

1 We assume that unemployment insurance is a fraction of the after tax real wage at some given employment level, for example full employment. Thus, if the real wage increases, the replacement rate decreases. An alternative assumption is that the replacement rate is constant. This leads to slightly more complex algebra below but has little effect on the results. 
dominates. The relation between $w_{h}$ and $L$ is depicted in Figure 1 .

Differentiating equation (4) and manipulating the result, the condition for being on the upward sloping portion of the locus in Figure 1 and thus for take home pay to be an increasing function of the level of employment can be expressed as :

$$
g>[(\alpha / \sigma)-b(1-\alpha)] /[1-\alpha+(\alpha / \sigma)-b(1-\alpha)]
$$

where $g$ represents the government's share of output, $\alpha$ is the share of capital in output, $b$ is the replacement rate provided by unemployment insurance and $\sigma$ represents the elasticity of substitution between capital and labor in production.

In the Cobb-Douglas case, if the effect of increases in employment on government spending is neglected, $(b=0)$, equation (5) reduces to the condition that $g>\alpha$, that the government's share exceeds the share of profit in GNP, a condition almost certainly satisfied in every European country. With a lower elasticity of substitution, condition (5) is still likely to be satisfied, especially when account is taken of the effects of increases in employment on the level of government spending. For example, assuming a capital share $\alpha$ of .25 , a replacement rate $b$ of .5 , and a government share of .4 , condition (5) will be satisfied as long as $\sigma>.28$, a condition which appears reasonable given most estimates of aggregate production functions. The following table gives the critical value of $g$ for different values of $\alpha, \sigma$ and $b . g$ must be larger than the value given in the table for $w_{h}$ and $L$ to be positively related. 
Table 1. Critical values of $g$ such that $w_{h}$ is an increasing function of $L$; $\alpha=.25$

$\begin{array}{llll}\sigma= & .0 & .33 & .67 \\ .33 & .50 & .40 & \\ .67 & .33 & .11 & .25 \\ 1.0 & .25 & .0 & .0\end{array}$

While the appropriate choice of parameter values is not clear, it appears likely that condition (5) will be satisfied. Thus, ncreases in employment in Europe are likely to coincide with higher after tax real wages. This is because the resulting increase in the size of the tax base and the implied lower tax rates will more than offset any reduction in the marginal product of labor.

Taxes and Employment

This conclusion raises further questions. If the government was to pursue expansionary policies, would not the effects on employment be magnified by the further reduction in tax rates due to the increase in employment? Could a tax cut even pay for itself? Addressing these questions requires us to close the model by adding a labor supply or wage setting equation to equations (1) to (3). We shall present in the next section a macroeconomic analysis of these issues. Here, we just consider two simple alternatives, the case of a fixed 
after tax real wage (a horizontal labor supply curve), and that of an inelastic supply of labor at a given level of employment (a vertical labor supply curve).

We start out by looking at the case of a rigid after tax real wage, so that we draw a horizontal labor supply curve in Figure 1 . This could result from extensive indexing. Alternatively, McDonald and Solow (1981) among others have argued that it could be the outcome of bargaining between unions and firms. Letting $w_{r}$ be the fixed reservation wage, so that $w_{h}=w_{r}$, we can solve for equilibrium employment as a function. of $w_{r}$ and $G$. In this case it is clear that there are in general two equilibria; both yield the same amount of revenue and the same after tax real wage; but they differ with respect to the level of employment. One of the equilibria is to the left of the point where take home pay is maximized: the marginal product of labor is high, but tax rates are also high. The other is to the right, the marginal product of labor is lower but this is offset by lower tax rates. As long as both equilibria are at less than full employment, the equilibrium $E^{\prime}$ in Figure 1 is obviously superior to the equilibrium E" since it involves the same level of take home pay for workers and increased employment. At the superior equilibrium $E^{\prime}$, tax revenues are an increasing function of the tax rate.

The comparative static properties of the two equilibria are quite different. A decrease in $G$ leads to a shift upwards of the after tax real wage employment locus. It leads therefore to a decrease in employment if the economy is initially at the low employment equilibrium, and an increase in employment if the economy is at the high employment equilibrium. It is also straighforward to show that, for the case where $b=0$, small decreases in the tax rate starting from the inferior equilibrium $E^{\prime \prime}$ increase tax revenues while, starting from $E^{\prime}$, they decrease tax revenues. The comparative static properties of $E$ " are 
FIGURE 1. TAKE HOME PAY AS A FUNCTION OF EMFLOYMENT

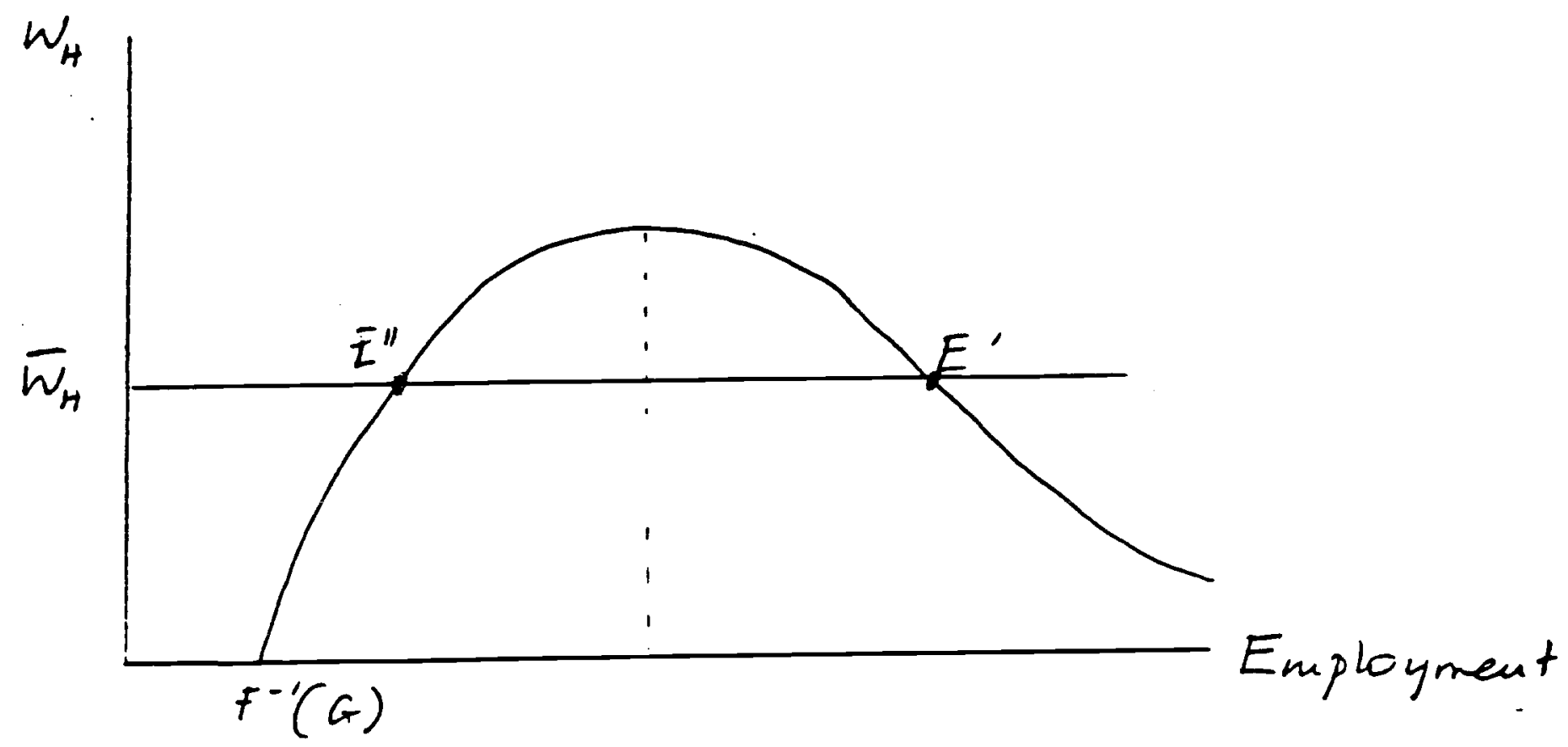

FIGUFE 2. THE CASE OF INELASTIC LABDF SUPFLY.

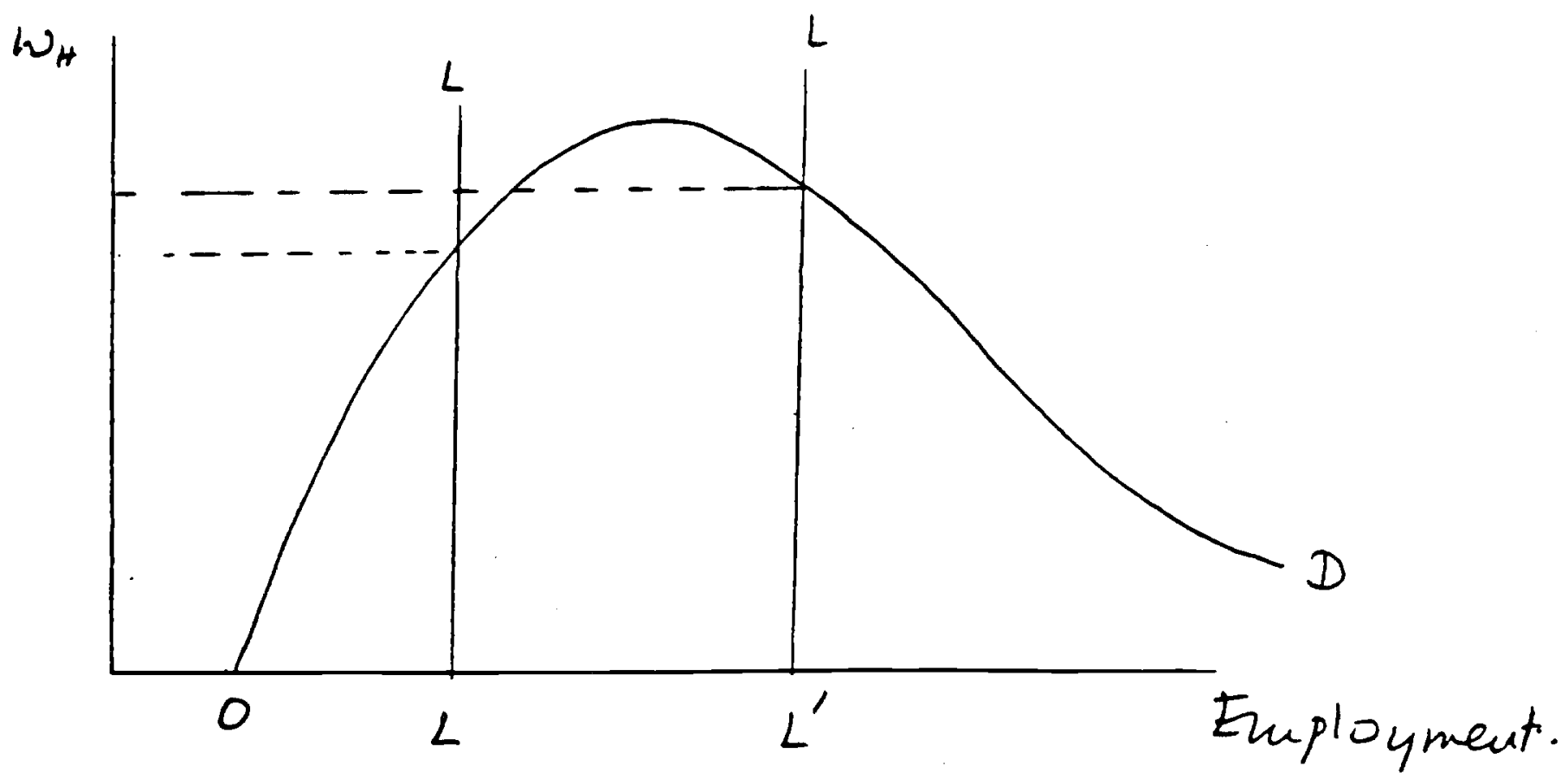


therefore rather strange and one is led to question whether E" is a stable equilibrium. Indeed it is not: starting at E", a reduction in employment leads to a tax increase, leading to further declines in employment and a downwards spiral; an increase in employment leads to a tax decrease, a further increase in employment and an upward spiral. 2

We have already argued that European economies are probably operating in the range where take home pay is an increasing function of employment. This rules out the equilibrium $E^{\prime}$. While it is tempting to conclude that economies will instead operate at the equilibrium E", we have seen that this is unlikely, as $E "$ is unstable. The correct conclusion is that, if the after tax real wage is really rigid, economies will either gravitate to the favorable stable equilibrium $E^{\prime}$ or will instead spiral downwards with ever increasing tax rates. It is difficult to predict the effects of decreases in tax rates or other expansionary policies in such a situation. They may, if large enough, change a downward spiral in an upward spiral, but it is difficult to predict the conditions under which this will occur.

These conclusions of course depend heavily on the assumption of real wage rigidity. If wage were instead set to maintain the current level of employment, even with the employment level far smaller than full employment, an assumption we sha11 argue later to be unfortunately closer to the truth in Europe, we would have the case depicted in Figure 2. Reductions in taxes would have no effect at all on employment and would simply lead to proportionate

2 The behavior of the Massachusetts economy over the last five years - which because of labor mobility within the US, largely takes its after tax real wage as given, is perhaps an actual example of such a virtuous circle. While obviously other factors than taxes are at work, Massachusetts' relative tax burden has decreased from above to below the national average, and output has sharply increased, increasing tax revenues. 
reductions in revenues. Even in this case however, if an employment expansion was achieved somehow, say by shifting LL to $L^{\prime} L^{\prime}$, it is still the case that it would allow for an increase in workers' take home pay.

\section{Some empirical evidence}

We end this section by first documenting the increase in tax rates which has taken place with the actual increase in unemployment, as it provides a kind of reverse experiment to the increase in employment and the decrease in tax rates we have discussed above. Secondly, we derive more realistic estimates of the decrease in tax rates which would be made feasible by a decrease in unemployment. These estimates are based on estimated Okun's law relations.

Table 2 gives the total share of tax revenues in GNP, and an estimate of the ratio of employees' take-home pay to employers' labor costs calculated from direct information on tax rates for the main EC countries for selected years from 1970 to 1984. The data show a consistent increase in the tax wedge in all countries. While many factors other than unemployment explain this increase, especially in the earlier part of the period, the increase since 1980 is substantial and probably mostly due to the relative shrinking of the tax base.

Table 3 answers the following question. Suppose that unemployment were reduced by 1 percentage point and the historical Okun's law relationship between unemployment and output held up. How large an increase in real take home pay would result if real product wages remained constant? Alternatively, how far could product wages decline with after tax real wages remaining constant? Estimates of Okun coefficients differ sometimes substantially depending on whether one regresses output on unemployment or unemployment on 
Table 2. Tax Burdens in Europe 1970-1984

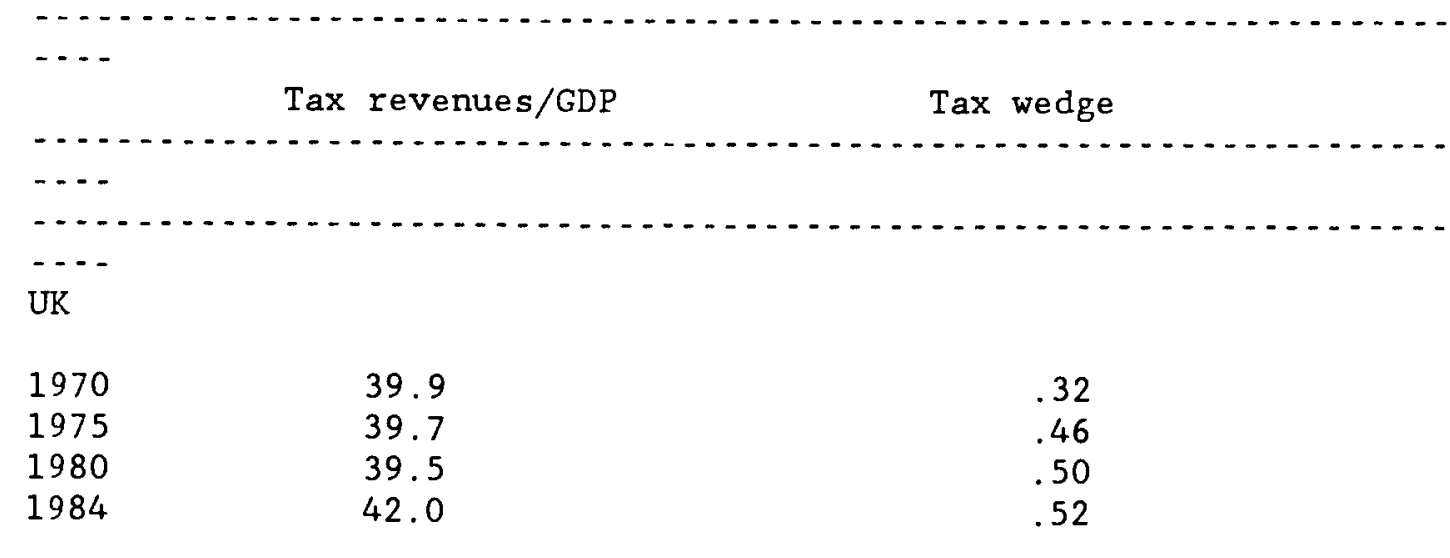

$-\cdots$

Germany

$\begin{array}{lll}1970 & 38.9 & .40 \\ 1975 & 43.3 & .45 \\ 1980 & 45.3 & .49 \\ 1984 & 46.4 & .51\end{array}$

-...

Italy

$\begin{array}{lll}1970 & 30.7 & .40 \\ 1975 & 31.6 & .38 \\ 1980 & 38.1 & .38 \\ 1984 & 45.4 & .43\end{array}$

France

$\begin{array}{ll}1970 & 39.8 \\ 1975 & 41.2 \\ 1980 & 46.6 \\ 1984 & 49.8\end{array}$

Sources : Column (1) is from the Annual Report of the EEC, November 1985, Table 45. Column (2) is constructed from the data appendix of the special issue of Economica, forthcoming, on unemployment. 
Table 3. The impact of a 18 reduction in unemployment of after tax real wages

(1)

Okun coefficient okun coefficient (optimistic) (pessimistic)

(3)

$t /(1-t)$
(4)

$(1) \times(3)$

$(5)$
$(2) \times(3)$

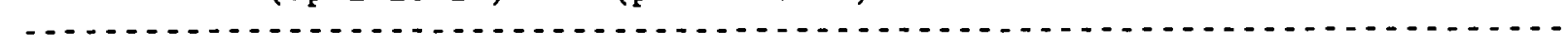

UK

4.3

1.5

.71

3.1

1.0

Germany

3.6

2.7

.99

3.6

2.7

Italy

6.2

3. 3

.83

5.1

2.7

France

5.5

3.8

.96

5.3

3.6

Notes : The number in column ( 1 ) is obtained by taking the reciprocal of the slope coefficient $b$ in the regression DU $-a+b$ DY, estimated with annual data for the period 1961-1985. The number in column (2) is obtained from the in verse regression. The value of $t /(1-t)$ is calculated using data on total government receipts as a share of GDP, using the Annual Report of the EEC, November 1985, table 45 . 
output $^{3}$. To avoid taking a stand on the issue of what specification is appropriate, we present estimates obtained under both sets of regressions. Even using pessimistic estimates, the potential for after tax wage increases is substantial, varying between 18 for the UK and 3.68 for France per point of unemployment reduction. It is extremely unlikely that product wages would have to decline by amounts nearly this large in order to achieve reductions of 18 in unemployment.

It seems clear that an expansion, if it could be engineered, would benefit both employed and unemployed workers. The question which remains is how this expansion could be engineered. This question is closely related to the problem of why, given that it would make the employed and unemployed alike better off, the economy does not spontaneously return towards full employment. We take this issue up in the next section.

3 Note that estimated Okun's law coefficients suggest a much greater impact of unemployment on GNP than is implied by the model presented earlier. This reflects the phenomena of short run increasing returns, changes in hours worked, and increased labor force participation which are neglected in the model. 


\section{Section II. The persistence of unemployment}

In the previous section, we argued that reductions in unemployment are likely to come with increases in the take home pay of employed workers. This raises the central problem of explaining why unemployment endures given that reductions would make both the employed and the unemployed better off. In order to consider this issue and to assess the efficacy of alternative policies directed at reducing unemployment, we begin by embedding the labor market model of the preceding section within a standard aggregate demand-supply macroeconomic framework.

\section{The standard framework}

We assume that the level of aggregate demand depends on the level of real money balances and on fiscal policy. Fiscal policy is sumarized by the deficit, which we take to be G-tY (that is, we ignore the presence of unemployment insurance--we put $b=0$ in equation (2) of the previous section-and ignore the presence of public debt). Thus :

(6) $\quad Y^{D}-D(G-t Y, M / P)$.

The aggregate demand curve, for given values of $G, t$ and $M$ is drawn in Figure 3 .

To derive aggregate supply, we follow the analysis of the first section by assuming that firms are competitive and employ labor to the point where marginal productivity and real wages are equal. For short run analysis, we close the model by postulating that nominal wages are rigid at the level $\mathrm{W*}$. 
FIGURE 3: THE STANDARD CASE

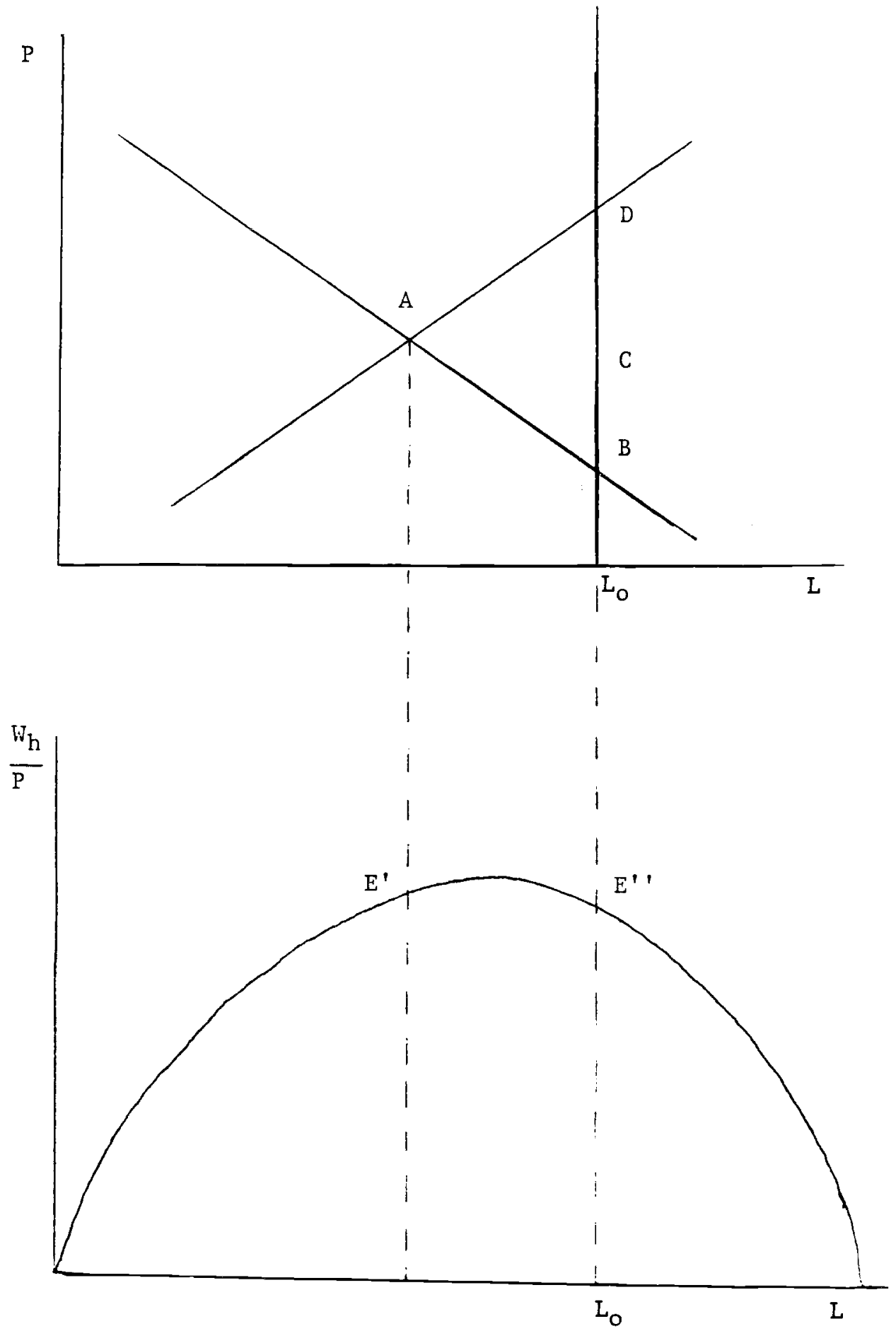


The implied short run aggregate supply, for given values of $W^{*}$ and $t$ is depicted in Figure 3. For the long run, we initially make the standard assumption that labor supply is inelastic and so $\mathrm{L}=\mathrm{L}^{0}$.

The short run equilibrium is at point $A$, with employment $L_{A}$. Associated with it is a fiscal deficit (or surplus). For any given level of deficit, say the level associated with this short run equilibrium, we can, using the analysis of the previous section and the locus derived in Figure 1, draw the after tax real wage consistent with a given level of employment. This is done in the lower part of Figure 3 and the after tax real wage associated with the short run equilibrium is given by point $E^{\prime}$. The long run equilibrium is somewhere on the vertical line going through $L_{0}$. If $G$ and $t$ are constant, the long run equilibrium is at point $B$, with a smaller deficit than at point $A$. If the tax rate $t$ is varied so as to maintain a constant deficit as employment goes to $\mathrm{L}_{0}$, the equilibrium is at a point like $\mathrm{C}$, and the after tax real wage is at point $\mathrm{E}^{\prime \prime}$.

If $L_{A}$ is less than $L_{0}$, the process of adjustment is likely to be as follows: unemployment puts pressure on nominal wages, and the decline in nominal wages shifts the aggregate supply curve to the right, increasing employment. If the government maintains a constant fiscal deficit, tax rates decrease. As we have drawn Figure 3, full employment is associated with higher after tax real wages.

The relatively slow rate of decline in inflation in many countries makes it unlikely that the European economies are operating far above the current natural rate of unemployment, that $L_{A}$ is far below $L_{0}$ in Figure 3 . Thus, one must conclude that the natural unemployment rate is probably not far from the actual rate. Indeed, most econometric evidence suggests that the natural and 
actual unemployment rates have roughly increased in tandem since the early 70's. There are two logically consistent explanations for this fact, each with different policy implications. We study them in turn.

\section{Supply shocks, real wage rigidity and unemployment}

The first explanation is that adverse supply shocks have pushed up the equilibrium rate and that the actual rate of unemployment has simply followed in tow. This argument is necessarily coupled with claims that real wages are rigid. For if real wages were flexible, supply shocks would not lead to changes in the level of unemployment.

If real wages are indeed rigid, even in the short run, we are back to the case analyzed earlier in Figure 1. We have seen that there are two levels of employment for any given after tax real wage. European economies are likely to be at levels of employment such that there is a positive relation between employment and take home pay; they are, however, unlikely to be at the lower, unstable equilibrium. In principle, a sufficient cut in taxes may lead the economy to the preferred equilibrium or to any level below it, if the higher equilibrium is at more than full employment. Tax cuts may then pay for themselves or more than pay for themselves. If, in addition to the long run rigidity of real wages, there is also some short run nominal rigidity, there is then scope for using demand policies to increase employment and make feasible in turn the reduction in taxes.

We are, however, skeptical of this line of explanation for the current levels of unemployment. While supply shocks may have merit as an explanation for European unemployment in the $1970^{\prime} s$, they cannot be the explanation for 
what has happened in the $1980^{\prime} \mathrm{s} .^{4}$ Supply conditions may not have been very favorable in 1980, but they have not gotten worse since then. Supply shocks taken alone do not appear sufficient to account for the doubling in both actual and equilibrium unemployment since 1980. This leads us to the second logical explanation of sustained high unemployment: adverse demand and supply shocks have increased the actual rate; this increase has in turn increased the equilibrium rate. We refer to theories which allow for a strong dependence of the equilibrium rate on the actual rate as hysteresis theories.

\section{Hysteresis in unemployment}

Hysteresis may result from the adverse effects of economic downturns on both physical and human capital accumulation, from the adverse effects of long term unemployment on workers' incentives to work, and from wage setting mechanisms which give employed workers disproportionate power in determining wages. All these effects probably play some role in creating a dependence of equilibrium on actual unemployment. We focus here on theories emphasizing the nature of the wage setting mechanism because we suspect that it is the most important channel of persistence.

In Blanchard and Summers (1986), we have put forward a theory of wage setting which is based on the distinction between insider and outsider workers stressed in a series of contributions by Lindbeck and Snower (1984, for

4 The role of supply shocks combined with real wage rigidity is the subject of Bruno and Sachs (1985). For a detailed and informative analysis of the role of supply shocks in the 1970's and 1980's, see Layard and Nickell (1986) for the UK and the papers in the special issue of Economica on unemployment (1986) for the other countries. 
example). 5 In unionized settings, this distinciton arises because the union determines the wage, only taking account of the interests of the median worker who is employed. We argue that the same phenomenon is also at work in non-union settings; in such settings, unemployed workers will be disenfranchised if currently employed workers have a significant amount of job specific capital or if they can credibly threaten to withhold cooperation from workers hired at low wages. To see the force of this point, consider how rarely firms replace their entire work force with low wage workers. In most cases the threat to do so is not credible. Note also how unsuccessful the introduction of the two tier system has been in Europe.

The macroeconomic implications of the assumption that wage bargaining is mainly in the interest of the currently employed are easily seen. Returning to our basic model, assume that the economy is composed of $\mathrm{N}$ identical competitive firms each producing subject to diminishing returns, and let us ignore for the moment issues of fiscal policy and taxes. Thus:

(7) $Y_{i}=F\left(L_{i}\right)$ and

(8) $F^{\prime}\left(L_{i}\right)-W_{i} / P$

where $i$ refers to firm $i$. Aggregate demand is given by :

(9) $Y=Y^{D}(M / P)$

and we assume, to start with, that $M$ is known at the time of wage setting.

Each firm inherits $\underline{L}_{i}$ workers who were employed by the firm in the previous period. Assume that incumbent workers at each firm have sufficient power to set wages at the highest possible level consistent with there all

5 A closely related model has been developed independently by Gottfries and Horn (1986). Sachs (1985) has also studied the macroeconomic implications of hysteresis. 
remaining employed. They will therefore choose a wage such that :

$$
F^{\prime}\left(\underline{L}_{i}\right)=W_{i} / P
$$

If they set a nominal rather than a real wage, wage setters must compute the appropriate value of $P$. As we have assumed $M$ to be known, and given that all firms are identical, $P$ is in turn given by :

$$
Y^{D}(M / P)=N F\left(L_{i}\right)
$$

Note the characteristics of the equilibrium. Whatever number of workers were employed last period will be employed this period : $L_{i}$ will be equal to $\underline{L}_{i}$, whatever $\underline{L}_{i}$. Put another way, aggregate supply will be vertical at a level of employment equal to last period's employment. This obviously comes from the assumption that the unemployed do not take part in the wage bargaining. If they did, higher unemployment would lead to lower nominal wages, lower prices, higher real money balances and output and employment until full employment was reestablished.

But this does not happen here. Note that the equilibrium just described is a Nash equilibrium under our maintained assumptions. Any group of workers that deviated from it by raising its wage would make itself worse off, as workers would be laid off. On the other hand, reductions in wages would create additional employment for others but not for group members and would therefore not be desirable. This simple model exhibits hysteresis in the sense that any history of employment levels that is inherited is perpetuated as a unique Nash equilibrium.

If the model is extended to allow for uncertainty in either aggregate demand or technology, and if nominal wages are set before the resolution of this uncertainty, the results extend straightforwardly. Given nominal wage rigidity, aggregate supply is upward sloping. But, in expected value, the level 
of employment is equal to last period's employment. ${ }^{6}$ High unemployment last period implies high expected unemployment this period.

In Blanchard and Summers (1986), we show how a theory along the lines of the one sketched above can explain the European unemployment record, with the increase in equilibrium unemployment being mostly due to supply shocks in the $70^{\prime} \mathrm{s}$ and demand shocks in the $80^{\prime} \mathrm{s}$. We show that, in addition to explaining how high unemployment can persist, such a theory can account for a number of aspects of recent experience. In particular, we show that under certain assumptions, the theory predicts that employment will evolve as a random walk regardless of the processes followed by supply or demand shocks. Employment in the major European countries has in fact evolved as a random walk over the last 15 years. We also show that the theory implies that accelerations in inflation should be much more closely related to changes in the rate of unemployment than to its level--an implication which is supported by data for Europe over the past 25 years.

\section{Hysteresis, real wages and fiscal policy}

Under the assumption of decreasing returns to labor and no taxes, the smaller the level of employment the higher the real wage and the better off the workers who remain employed. Thus, an increase in employment does not make both the employed and the unemployed better off. However, this result is easily

6 This statement is an oversimplification. The presence of uncertainty complicates the decision problem of insiders, and expected employment may well be different from previous emploment (see Blanchard and Summers 1986). There remains however a strong dependence of this period's aggregate supply curve on last period's actual employment. 
overturned when we reintroduce fiscal increasing returns and incorporate the analysis of the first section. If we assume that the government has a fixed level of spending which it raises through a proportional tax on all output, the tax rate is a decreasing function of employment. If as we argued in the first section, the effect of reduced taxes on take home pay exceeds the effects of diminishing returns, it follows that equilibria associated with higher levels of employment involve higher after tax real wages. In this case, all workers would be better off if those who are currently employed accepted a nominal wage reduction: the price level and the tax rate would fall enough to make after tax real wages increase. But it is still not in the interests of workers at any one firm to cut their wages. The economy is therefore locked into an inferior equilibrium. In terms of Figure 2 earlier, the economy is stuck at the low LL while everybody would be better off if the economy was at $L^{\prime} L^{\prime}$ instead.

\section{Hysteresis and the Efficacy of Expansionary Policy}

What does the hysteresis theory imply about the efficacy of expansionary policies in reducing employment? We first consider the case where there are no nominal rigidities. In this case, depicted in Figure 4, the aggregate supply curve is vertical at the previous level of employment. Incumbent workers will simply raise wages if expansionary policies are attempted. While incumbent workers collectively would be better off if they did not increase nominal wages in the face of expansionary policies, each individual group of incumbent workers has an incentive to raise its own wages.

Allowing for some nominal rigidity as in Figure 5, so that product wages are set before policies are chosen, gives expansionary policy scope to increase 
FIGURE 4

HYSTERESIS WITHOUT NOMINAL RIGIDITY

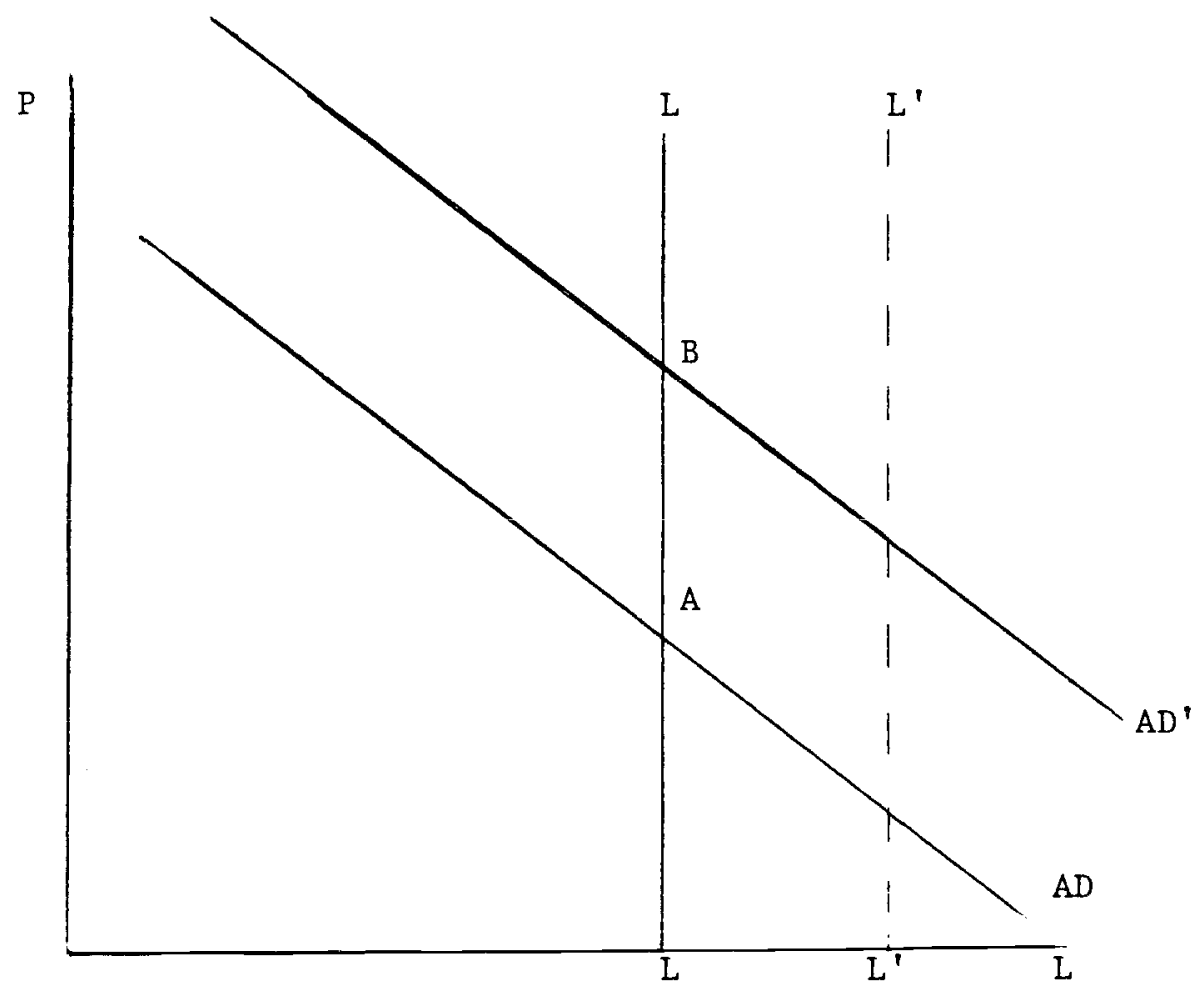

FIGURE 5

HYSTERESIS WITH NOMINAL RIGIDITY

$\mathrm{P}$

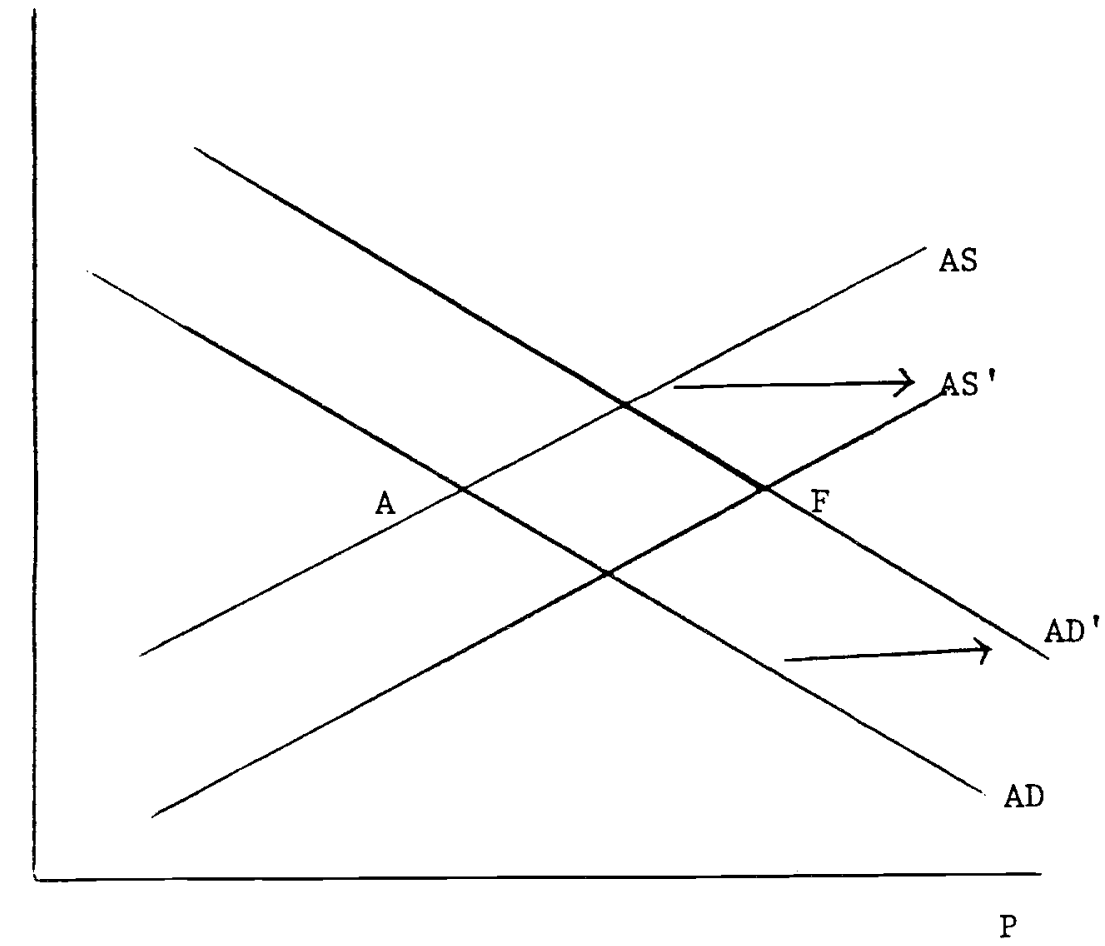


employment. A decrease in tax rates, for example, shifts aggregate demand, because of a higher deficit at any employment level, and aggregate supply, because of the decrease in tax rates. Expansionary policy can therefore shift the economy from $A$ to a point like F. Because of the dependence of the subsequent level of wages on the number of incumbent workers, any employment gains produced by expansionary policies are likely to be durable. The crucial question becomes the horizon over which it is possible to surprise workers and change employment through demand policies. The experience of the last few years suggests that this horizon may be long enough to allow expansionary policies to have significant effects on employment. Certainly the contractionary policies of the last several years have had significant and protracted adverse effects on the level of employment.

Assuming that the economy's current state is dominated by another equilibrium with higher employment, higher after tax real wages and the same fiscal deficit, and assuming nominal wage rigidity in the short run, can a decrease in tax rates take the economy from the current equilibrium to the other? To answer this, we return to Figure 3. In Figure 3, the current equilibrium is at point $A$, the preferred one at a point like $C$. To go from $A$ to C requires shifts in both aggregate supply and in aggregate demand. This has the following implications:

A decrease in tax rates which did not shift the short run aggregate supply curve, such as a decrease in direct taxation (which would not affect the aggregate supply if the nominal wage was fixed), would lead to an equilibrium such as D, with higher employment, but a higher deficit as well. A decrease in taxes levied on firms would instead shift the aggregate supply, decrease the price level at any level of employment, increase real money balances and lead 
to a lower deficit at the level of employment $\mathrm{L}_{0}{ }^{7}$. Thus, on these grounds, cuts in payroll taxes levied on firms are preferable to income tax cuts.

While cuts in taxes levied on firms will in general shift both aggregate demand and short run aggregate supply, there is no guarantee that the resulting equilibrium will be the prefered one, point $C$. It is in particular straightforward to show that $C$, the point at which the deficit is unchanged, is attained only if the net effect of aggregate supply and aggregate demand is to decrease the price level given nominal money. This suggests that fiscal policy may usefully be reinforced by monetary policy. The preferred equilibrium can then be achieved without a decrease in the price level.

7 Poterba, Rotemberg and Summers (1986) provide evidence that reductions in indirect taxes in fact have more substantial effects on output than do reduction in direct taxes on laborers. They also find that reductions in prices result from reductions in indirect taxes unlike reductions in direct taxes. 


\section{Conclusions}

It appears clear that there exist equilibria with higher employment, higher take home pay for employed workers, and lower government budget deficits than the equilibrium where Europe now sits. The problem for policy is to make the transition. Our analysis suggests that tax cuts are very likely to be effective. Depending on the way in which product wages are set, it is conceivable that they could be self financing without any accomodating policy changes. More likely, tax cuts would lead to deficits in the short run, and would require expansionary monetary policies to realize their full supply side benefits. But the end result would be increases in employment and real wages without increases in government budget deficits.

There is a broader point as well favoring the use of tax reductions as an element of policy packages directed at combatting unemployment. Asking workers to restrain wage demands on the promise that if they all comply, tax rates will be able to fall and increases in employment and real wages will result is probably hopeless. But it may be possible to trade wage restraint for tax reductions explicitly, especially in countries where collective bargaining is relatively centralized. This is likely to require some willingness to accept increased budget deficits at least in the short run. The alternative line of attack on unemployment is to pursue policies which enfranchise as many of the unemployed as possible and reduce the power of incumbents. Worksharing plans which increase the number of employed workers may have the effect of enlarging the incumbent groups that set wages thereby 
leading to lower wages, and greater employment. An obvious alternative policy is measures to reduce the power of unions and insider groups more generally and thereby allow outsider workers to have a larger impact on wage bargains. These measures are likely to be much more socially acceptable if the case can be made that increases in employment will not be associated with reductions in the compensation of the currently employed. Tax cuts are likely to make this proposition much more credible to the affected workers. 


\section{REFERENCES}

Blanchard, O. and L.H. Summers, (1986) "Hysteresis and the European Unemployment Problem," forthcoming NBER Macroeconomics Annual (ed. S.Fischer)

Blanchard, O. and L. H. Summers (1987) "Hysteresis in Unemployment" forthcoming in European Economic Review.

Bruno, M. and J. Sachs (1985), "Economics of Worldwide Stagflation", Oxford, Basil Blackwell

Gottfries N. and H. Horn, (1986) "Wage Formation and the Persistence of Unemployment", WP 347, Institute for International Economic Studies, Stockholm

Layard, R. and S. Nickell, (1986) "The Performance of the British Labour Market", paper presented at the Chelwood Gate Conference on the British Economy, May

Lindbeck, A. and D.J. Snower, (1984) "Involuntary Unemployment as an InsiderOutsider Dilemma", Seminar Paper No. 282, Institute for International Economics, Stockholm

Poterba, J. J. Rotemberg and L. Summers, (1986) "A Tax Based Test for Nominal Rigidities"American Economic Review, September

Sachs, J., (1985), "High Unemployment in Europe", Harvard mimeo 